\title{
Declining Agricultural Productivity and Global Food Security
}

\author{
WILLIAM D. DAR and C. L. LAXMIPATHI GOWDA \\ International Crops Research Institute for Semi-Arid Tropics (ICRISAT), \\ Patancheru, Andhra Pradesh, India
}

It is imperative that the world's farmlands become the frontline for the battle to feed the projected 9 billion population globally. The detrimental effects of climate change on food security can be counteracted by broad-based economic development_particularly enhanced agricultural investment for improved land, water, and nutrient use. Improved crop, soil, and water management practices and stress-tolerant varieties that will overcome the detrimental impacts of climate change will lead to benefits like improved food security, liveliboods, and environmental security. Among the agricultural systems at greater risk of climate change are the dryland tropics, where the International Crops Research Institute for the Semi-Arid Tropics (ICRISAT) has its mandate. ICRISAT's new Strategy to 2020 lays emphasis on inclusive market-oriented development (IMOD) as a pathway out of poverty by linking farmers to markets to increase incomes, enabled through a systems perspective and purposeful partnerships. ICRISAT aims to build resilient dryland systems through its research thrust on reducing vulnerability to drought, heat, and other climate change scenarios. ICRISAT's many major milestones on its climate-responsible path have been its short-duration chickpea varieties that have enabled an expansion of the crop into tropical latitudes in Asia and Africa, sustainable soil management practices such as microdosing, conservation agriculture, and initiatives such as the Sabelian Eco-Farm and knowledge-based and people-centric entry-point activities in its community-based watersheds.

Received 15 December 2011; accepted 20 December 2011.

Address correspondence to C. L. Laxmipathi Gowda at International Crops Research Institute for the Semi-Arid Tropics (ICRISAT), Patancheru, Hyderabad-502324, Andhra Pradesh, India. E-mail: c.gowda@cgiar.org 
KEYWORDS Global food security, sustainable agriculture, rainfed agriculture, climate change impact

\section{INTRODUCTION}

The three defining and interlinked challenges of the 21st century are managing climate change and overcoming poverty and food insecurity, bringing them to the top of the international agenda. In 2008, the world was witness to a food-price spike, to food riots and political change in several countries. In India, the monsoon failure in 2009 knocked out 40\%-50\% of kharif harvest; torrential downpours worsened the food crisis. Pakistan was ravaged by unprecedented floods with a massive impact on agriculture and food production. In Niger, drought and failed harvests put more than half the country's population of 14 million at risk from famine.

Climate change predictions point to a warmer world within the next 50 years. All scenarios now show average temperature increases by 2050 to be in the order of $1^{\circ} \mathrm{C}$. After that, they diverge dramatically, ranging from $2^{\circ} \mathrm{C}$ to $4^{\circ} \mathrm{C}$ by 2100 . Yields of many more crops will be severely threatened then. Though according to the Intergovernmental Panel on Climate Change (IPCC), the impact of rising temperatures on rainfall distribution patterns in Africa and Asia remains far less certain; in some parts of the world, the increasing frequency of extreme rainfall events and droughts appears significant. So unless the livelihood resilience and adaptive capacity of vulnerable communities can be greatly increased, adapting to future climate change will be daunting for most and impossible for many.

\section{CLIMATE CHANGE: SEVERITY AND IMPACT}

Given the fact that two billion people already live in the driest parts of the globe, where climate change is projected to reduce yields even further, the challenge of feeding nine billion mouths by 2050 is daunting! This will mean that global agricultural production will need to grow by $70 \%$ to $100 \%$ by then! And what does it imply for about 1.5 billion people, nearly $60 \%$ of developing nations' workforce, who are engaged in agriculture? Because agriculture constitutes a much larger fraction of gross domestic product (GDP) in developing countries than in developed nations, even a small percentage of loss in agricultural productivity could snowball into a larger proportionate income loss for developing countries than in the industrialized countries. The latest research from International Food Policy Institute (IFPRI) predicts that without action by 2050 , food prices could rise by up to $131 \%$ for maize, $78 \%$ for rice, and $67 \%$ for wheat! 
In more than 40 poor developing countries, with a combined population of 2 billion, there are 450 million undernourished people. The Asian drylands house $42 \%$ of malnourished children and the sub-Saharan African drylands 27\%. Production losses attributable to climate change may drastically increase their numbers, severely hindering progress against food insecurity.

Climate change also threatens poverty-reduction efforts as the poor depend directly on already fragile ecosystems for their well-being and livelihoods. They lack the resources to adequately defend themselves or to adapt rapidly to changing circumstances, and more importantly, their voices are not sufficiently heard in international discussions, particularly in climate change negotiations. Environmental effects triggered by climate change, such as desertification and rising sea levels, can lead to increased conflict for resources.

While agriculture is highly vulnerable to changes in climate, at the same time, it is an important source of greenhouse gas (GHG) emissions, representing $14 \%$ of the total global emissions. From 1990 to 2005, emissions from agriculture in developing countries increased $32 \%$ and are expected to continue to rise, driven by population increases and changes in diet (Food and Agriculture Organization 2009). While emissions from factors such as fertilizer production and application have increased, the net effect of higher yields has avoided emissions of up to 161 gigatons of carbon (GtC) since 1961. It is estimated that each dollar invested in agricultural yields has resulted in 68 fewer $\mathrm{kgC}$ emissions relative to 1961 technology, avoiding 3.6 GtC per year (Burney, Davis, \& Lobell 2010).

Hence agriculture has the potential to adapt and mitigate the impacts of climate change, and $70 \%$ of its high technical mitigation potential could be realized in developing countries. This is possible through adoption of sustainable practices, such as improved soil, crop. and water management. Agriculture can also serve as a potential sink for carbon and contribute to the resilience needed by smallholder farmers to adapt to and withstand the impacts of climate change.

The negative effects of climate change on food security can be counteracted by broad-based economic growth-particularly improved agricultural productivity, robust international trade in agricultural products that can offset regional shortages, and agricultural productivity investments. For instance, an increase in maize productivity of 2\% per year through 2050 would give a 12\% price increase and reduce the number of malnourished children by $3 \%$ to $5 \%$.

It is widely recognized that the increased heat stress, shift in monsoons, and drier soils pose much greater threats to the tropics than the temperate regions. With most developing countries located in the tropicsand most of them being heavily dependent on agriculture for food and income-relatively poor countries with limited resources face the costly and 


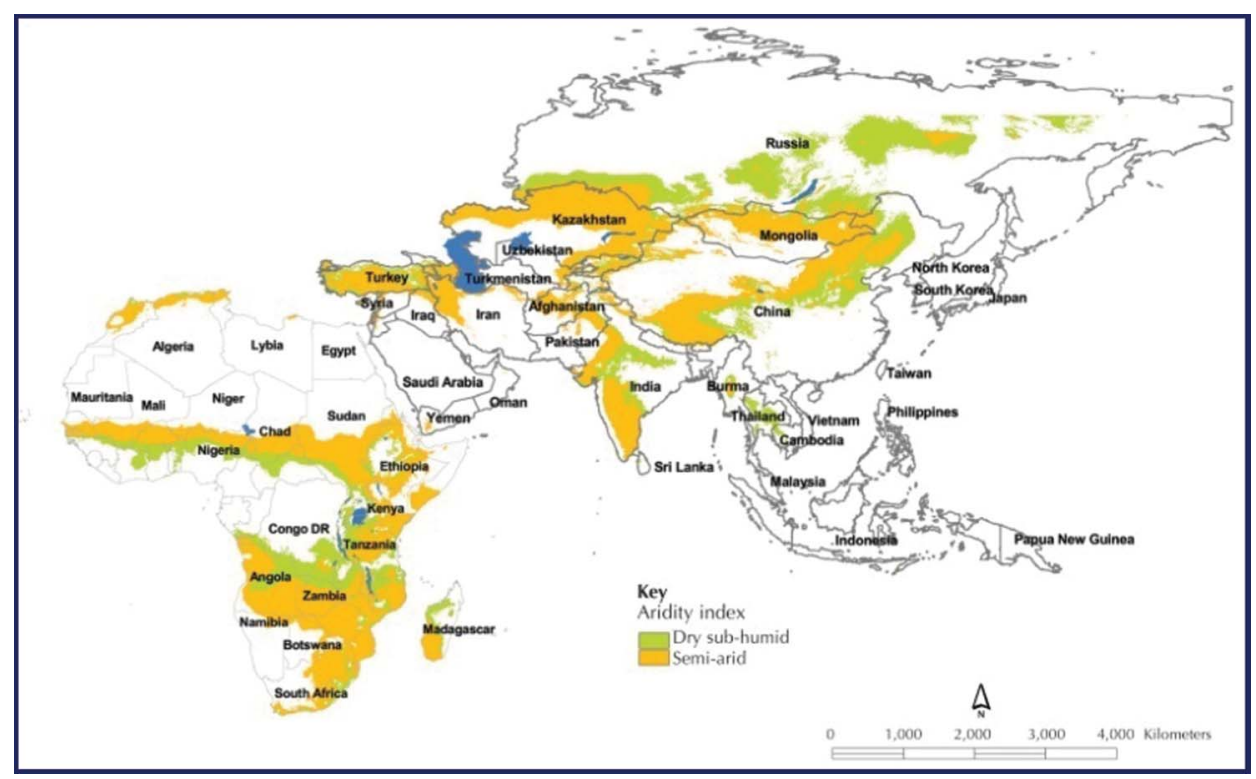

FIGURE 1 Projected tropical drylands of Africa and Asia in the year 2050, based on climate change models. The dryland tropics were delineated using the Aridity Index of the FAO and UNESCO (color figure available online).

formidable task of adapting to climate change. The geographic focus of the International Crops Research Institute for the Semi-Arid Tropics (ICRISAT) is the semi-arid tropics or tropical drylands, which span 6.5 million square kilometers covering more than 55 countries and are home to more than 2 billion people. The tropical drylands have a challenging and inhospitable terrain where agriculture is risky. Figure 1 illustrates one of the many possible scenarios of projected tropical drylands of Africa and Asia in the year 2050, based on climate change models. The maps were produced starting with year 2000 data from the CRU-TS 3.0 Climate Database and using the HADCM3 output of the A2a scenario to determine the year 2050 areas. The dryland tropics were delineated using the Aridity Index of FAO and UNESCO.

Characterized by extreme rainfall variability, recurrent and unpredictable droughts, flooding, high temperatures, and a fragile natural-resource base with inherent low fertility soils, the rising perfect storm-a confluence of climate change, desertification, biodiversity loss, rising prices, and mounting poverty and population - further threatens to disrupt the lives of the poor in the drylands who depend on agriculture for survival.

Global momentum is increasing for an approach to environmental protection based on the 'ecosystem services' that nature provides for humans. As long as the marketplace treats such services as free goods, nature's services to humanity will effectively be set to zero. By pricing such services, 
all the forests, streams, lakes, and seashores would suddenly acquire real economic value. People will then have incentive to preserve them.

\section{STRATEGIES TO ALLEVIATE THE EFFECTS OF CLIMATE CHANGE}

With climate change being a threat multiplier, adaptation and mitigation strategies need to be urgently integrated into national and regional development programs. Developing countries need to participate in a globally integrated approach to this problem. Policies for adaptation include changes in land use and timing of farming operations, adaptive plant breeding and crop husbandry technologies, pest forecasting and pest-management technologies, irrigation infrastructure, water storage, and water management. Mitigation measures may include improved crop- and livestock-management practices, including improved input-use efficiencies (such as fertilizer microdosing and need-based application of pesticides for pest management), cropping systems diversification, improved water management, and better forecasting tools and early warning systems.

\section{CLIMATE CHANGE-READY CROPS}

ICRISAT already has on hand: crops that are adapted to high soil and air temperatures; knowledge and understanding of flowering maturities; information on genetic variation for water-use efficiency; short-duration varieties that escape terminal drought; and high-yielding and disease-resistant varieties. For instance, we have developed short-duration chickpea cultivars ICCV 2 (Shweta), ICCC 37 (Kranti), JG 11, and KAK 2; short-duration groundnut cultivar ICGV 91114 that escapes terminal drought (Figure 2) and also super-early chickpea and pigeon pea lines that mature in about 65 to 75 days. Short-duration chickpea varieties have enabled the expansion of the crop into tropical latitudes in Asia and Africa.

ICRISAT and private sector partnership's pearl millet hybrids 9444 and $86 \mathrm{M} 64$ flower and set seed at temperatures as high as $44^{\circ} \mathrm{C}$. ICRISAT-bred sorghum hybrid seed parents show stable seed set at temperatures above $40^{\circ} \mathrm{C}$. Sorghum genotypes with the stay-green trait continue to fill their grains normally even under limited water or moisture-stress conditions (Borrell, Hammer, \& Douglas 2000). ICRISAT-developed sorghum hybrid parents ICSR 21002, ICSV 21011 and ICSB 371 are high yielding and possess the stay-green trait that provides drought tolerance (Reddy et al. 2007).

Our screening for heat tolerance in chickpea by growing the crop in the summer season has revealed wide variation for heat tolerance. One of the best heat-tolerant lines identified was ICCV 92944, which was earlier released as Yezin 6 in Myanmar. 


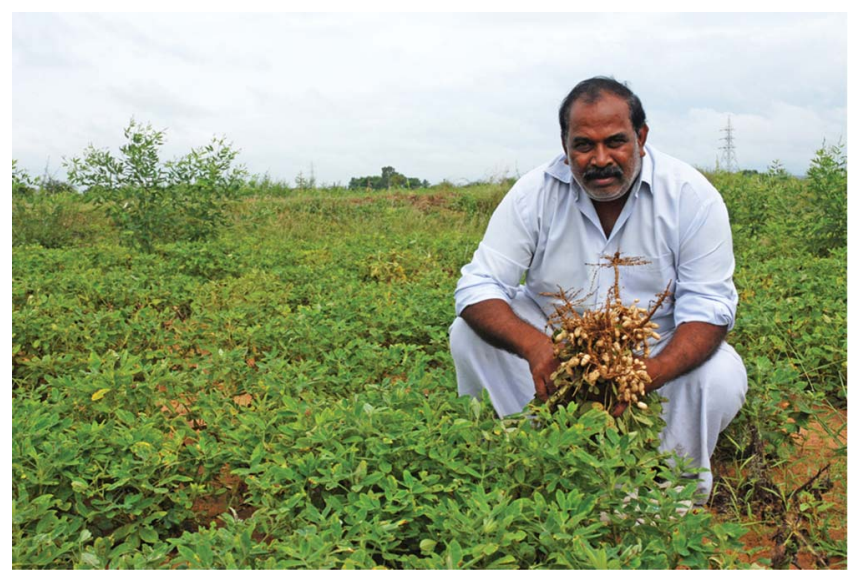

FIGURE 2 ICRISAT's climate-smart short-duration groundnut cultivar 'ICGV 91114' escapes terminal drought (color figure available online).

What we need to better understand is the physiological mechanism underlying heat tolerance, and to identify wider gene pools to develop crops with wider adaptability and to develop more effective germplasmscreening techniques for desired traits. ICRISAT's gene bank holds more than 119,000 accessions from 144 countries that will help safeguard and exploit genetic diversity to enhance adaptation.

\section{CLIMATE-SMART PRODUCTION SYSTEMS}

\section{Water Management}

Climate change will modify rainfall, evaporation, runoff, and soil-moisture storage, whereas higher temperatures will lead to an increase in crop water requirements. Improving crop production under such a scenario will largely depend on overcoming soil moisture problems through better capture and storage of rainwater and through improved use efficiency.

In the tropical drylands, seasonal rainfall is generally adequate to significantly improve yields, but managing the extreme rainfall variability in time and space is a tremendous challenge. Managing water and using it efficiently are the main yield determinants.

ICRISAT's participatory and knowledge-based watershed development programs in Andhra Pradesh, Gujarat, Madhya Pradesh, Rajasthan, and other states in India and parts of southern China, northern Vietnam, and northeast Thailand have shown that farmer and public investment can provide attractive social returns, leading to poverty reduction. The success of the Adarsha Watershed model in Kothapally in Andhra Pradesh, India, has attracted farmers, policymakers, and development investors. Income-generating options for the landless and women at Kothapally and other benchmark watersheds 
have included the setting up of village seed banks through self-help groups; value addition through seed material; product processing, such as dal making, grading, and marketing; poultry rearing for egg and meat production; and vermi-composting. An average household income of US\$1,066 was generated from crop diversification and other systems in the watershed compared with US\$734 in the non-watershed areas, reflecting an increase of 45\% attributable to watershed interventions.

Similarly, the Lucheba watershed in Guizhou province in China saw improved productivity with the adoption of cost-efficient water-harvesting structures, farming system diversification, and intensification from rice and rapeseed to tending livestock and horticultural crops. Following watershed interventions, mainly growing vegetables and other diversified activities like tending chicks and pigs, the average income of farmers increased threefold, from US\$462 (before the interventions) to US $\$ 1,538$. The development of community watersheds in China and India has resulted in crop yields increasing up to four-fold and incomes rising by $45 \%$ and $77 \%$, respectively.

\section{Crop Management Practices}

Adaptation to climate change necessitates identifying more appropriate cropmanagement practices; many of them are extensions of those currently being used or promoted to increase crop production. Warmer temperatures lead to rapid plant growth, resulting in a significant reduction in plant biomass and yield. For most crops, improved varieties adapted to a wide range of climatic conditions are available, and the impacts of climate change can be mitigated to some extent by redeploying and retargeting existing germplasm.

Reduced tillage, conservation agriculture, microdosing of fertilizers, need-based application of pesticides, and use of legumes in crop rotations are some promising and economically viable technologies. Such technologies can reduce risk, improve soil fertility, and enhance productivity under variable climatic conditions.

\section{Integrated Pest Management}

Greater variability in climate will mean increased variability in pest incidence. Many of the pests that are presently confined to the tropics may move northward to the temperate regions in Europe and North America. Changes in the distribution of insect pests will be greatly influenced by changes in the range of host crops because the distribution of a pest is also dependent on the availability of a host.

Developing cultivars with stable or durable resistance to pests will provide an effective approach in pest management. Resistance to sorghum midge (Stenodiplosis sorghicola) breaks down under high humidity and moderate temperatures in Kenya, whereas stem borer severity increases under drought (Sharma et al. 1999). Therefore, it is important to identify 


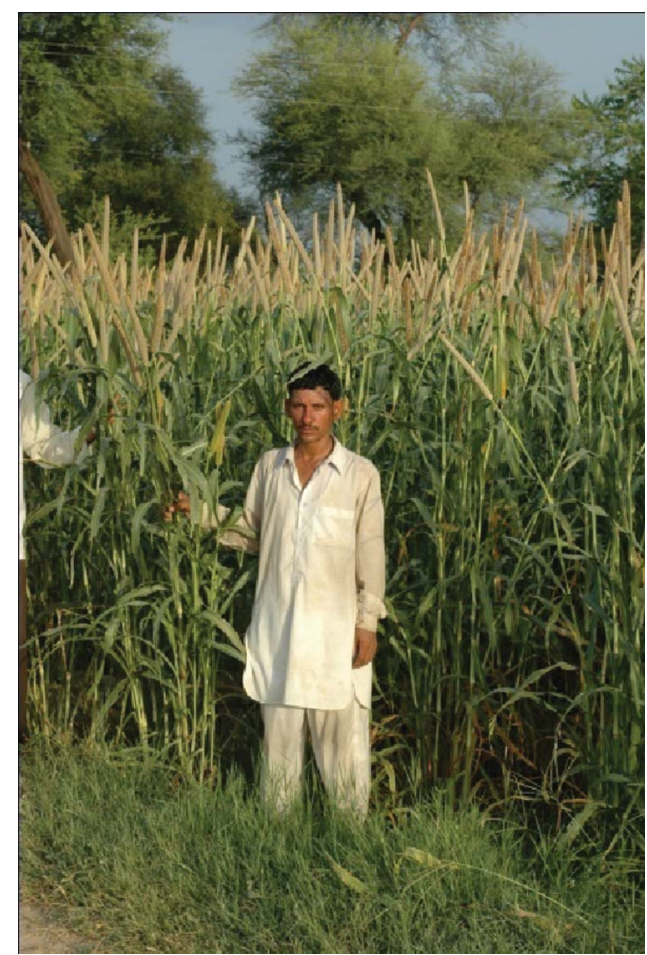

FIGURE 3 A farmer shows off his downy mildew-free crop of pearl millet hybrid 'HHB 67-Improved' (color figure available online).

and develop cultivars that are stable in expression of resistance to the target pests under variable climate. Relationships between pests and their natural enemies will change as a result of global warming, resulting in both increases and decreases in the status of individual species. Quantifying the effect of climate change on the activity and effectiveness of natural enemies will be a major concern in future pest-management programs.

ICRISAT has developed crop varieties that resist pests and pathogens. For example, downy mildew-resistant pearl millet hybrid 'HHB 67-Improved' (Figure 3) in India; wilt-resistant high-yielding pigeonpea ICEAP 00040 in Tanzania, Malawi, and Mozambique; and rosette-resistant groundnuts in Uganda, to name a few.

\section{INTEGRATED NUTRIENT MANAGEMENT}

It is estimated that over 815 million households worldwide suffer from micronutrient deficiency. Our main objective is to increase the bioavailability of $\mathrm{Zn}$ and $\mathrm{Fe}$ micronutrients and beta-carotene in the grains of ICRISATmandate crops through biotechnological and conventional breeding. The feasibility of producing pearl millet hybrids combining high grain yield and 
high $\mathrm{Fe}$ content is being tested in multilocational trials at ICRISAT using high-Fe seed parents and restorers. Results have shown that even with the exploitation of existing hybrid parents that had not earlier been bred for higher Fe content, good possibilities exist to develop high-Fe hybrids with grain yield competitive to commercial hybrids.

ICRISAT is developing mycotoxin-tolerant cultivars, particularly groundnut, and appropriate pre- and post-harvest technologies that reduce the risk of food/feed contamination. This is being done through both conventional plant breeding and biotechnology applications, and simple and low-cost mycotoxin diagnostic tools.

\section{ECONOMIC DIVERSIFICATION, CAPACITY BUILDING, AND COLLECTIVE ACTION}

Diversification of crops cultivated by smallholder farmers in the semi-arid tropics has the potential to increase household income, create a more nutritious household diet, and provide remunerative labor opportunities as well as valuable by-products, such as firewood, fiber, and fodder.

Crop diversification by introducing legumes into rice/wheat fallows pursued in the Indo-Gangetic plains of South Asia, growing medicinal and aromatic plants in partnership with private sector companies, and systems diversification through mixed crop-livestock systems have served as coping strategies against risk and also enhanced incomes. Crop residues of chickpea, groundnut, pigeon pea, sorghum, and millet are important sources of animal feed throughout the year, notably in the dry months when other feed resources are scarce. Improving the digestibility of such crop residues can have a significant impact on milk production, particularly in South Asia. For example, haulm or stems of a groundnut variety led to a $20 \%$ increase in milk yield of dairy animals of farmers who adopted this improved variety in Andhra Pradesh.

The African Market Gardens (AMGs) concept combines low-pressure drip-irrigation systems with high-value crop diversification, enabling the commercial integration of fruit, vegetables, and trees in the dry Sahel. Women's groups can tend these small "market gardens" to both increase their incomes and diversify their family's diet, multiplying their incomes by several-fold-in some cases more than tenfold to US $\$ 1,500$ from an area of only 500 square meters.

\section{WEATHER FORECASTING AND CROP MODELING}

The role of weather and climate services and products in developing adaptation solutions is crucial. In the semi-arid tropics, the greatest challenge 
to rainfed farming is to deal with the variability in rainfall, both within and between seasons, and extremes of temperature and humidity regimes, that will have a substantial effect on crop growth, pest incidence, and crop productivity.

Use of climatic forecasts in farm-level decision making has remained underdeveloped. Conditions that must be in place for farmers and other agricultural decision makers to realize the potential benefits of appropriate use of climate forecasts include decision-maker awareness of vulnerability and motivation; viable decision options that benefit from forecast information; prediction of the components of climate variability that are relevant to decisions, adequate communication, and understanding of relevant information by the right audience at the right time; and, in the longer-term, appropriate institutional commitment and policy support (Hansen 2002). Climate-change assessment tools are needed that are more geographically precise, that are more useful for agricultural policy and program review and scenario assessment, and that more explicitly incorporate the biophysical constraints that affect agricultural productivity. Guiding crop adaptation work are tools such as INSTAT and GENSTAT, MARKSIM, and APSIM/DSAT that analyze climate data and produce high-quality information and products tailored for agricultural applications and to quantify the relationships between climate, crop, soil, and water resources.

\section{CLIMATE CHANGE: HOPE FOR THE SEMI-ARID TROPICS}

Using a range of weather data-driven tools, ICRISAT's scientists have initiated research to test the hypothesis that, in the medium term (2010-2050), we are well placed to help farmers mitigate the challenges and exploit the opportunities posed by climate change. Yield gap analyses have shown that the negative impacts of climate change can be largely mitigated through greater application by farmers of improved crop-, soil-, and water-management innovations and better targeted cropimprovement approaches more explicitly focused on adaptation to climate change.

The impact of climate change on yields under low-input agriculture is likely to be minimal as other factors will continue to provide overriding constraints to crop growth and yield. The adoption of currently recommended, improved crop-, soil-, water-, pest-management practices, even under climate change, will result in substantially higher yields than farmers are currently obtaining under low-input systems. Adoption of better 'temperature-adapted' varieties could result in complete mitigation of climate change effects that result from temperature increases. Policymakers 
should take notice of the fact that better formulated and targeted policies that facilitate and support the adoption of agricultural innovation today assume even greater urgency. Not only will they improve the welfare of rural populations today, but they will also do a great deal to mitigate the impacts of future climate change.

\section{INCLUSIVE MARKET-ORIENTED DEVELOPMENT (IMOD)}

Developing countries in Asia and Africa are witnessing a fundamental shift in agriculture from farming for household consumption to a more marketoriented production, where consumer-driven supply chains will play a dominant role, unlike the erstwhile product-oriented supply chains. Thus, procurement and marketing of agricultural commodities are witnessing institutional innovations like contract farming, bulk marketing through producers' associations, direct marketing, marketing through cooperatives or specialized middlemen, and ICT-enabled supply chains that directly link the producer to the end user.

Analyses by the World Bank and ICRISAT have found that access to markets is key to escaping poverty. Gleaned from our rich knowledge base spanning 38 years in partnership with institutions, strategic studies, and longterm village-level studies, we have found that changes have occurred across three decades in a number of villages in drylands in Africa and Asia. Where poverty is declining, it has been largely because of improved connections to urban markets that purchased agricultural produce and offered additional employment opportunities.

ICRISAT's new Strategy to 2020 is about harnessing markets to achieve our four mission goals: to elevate the poor out of poverty, hunger, malnutrition, and environmental degradation across the dry tropics of the developing world, aided by purposeful partnerships. The strategy, anchored on inclusive market-oriented developmen—or IMOD for short—can be summarized in three simple words: innovate, grow, and prosper (Figure 4).

The IMOD is a socio-economic process and a dynamic progression from subsistence toward market-oriented agriculture, which will achieve a new level of access to resources, stability, and productivity for poor smallholder farmers. ICRISAT's contribution to IMOD through its Strategic Thrust on Resilient Dryland Systems aims to help the poor navigate the pathway out of poverty by reducing their vulnerability to drought and climate change while increasing diversity and value. The IMOD pays greater attention to women, the largest group of poor and hungry, whose children are the dryland's future and who are at risk of being left behind by markets. It is also about building resilience, the ability to withstand and recover from 


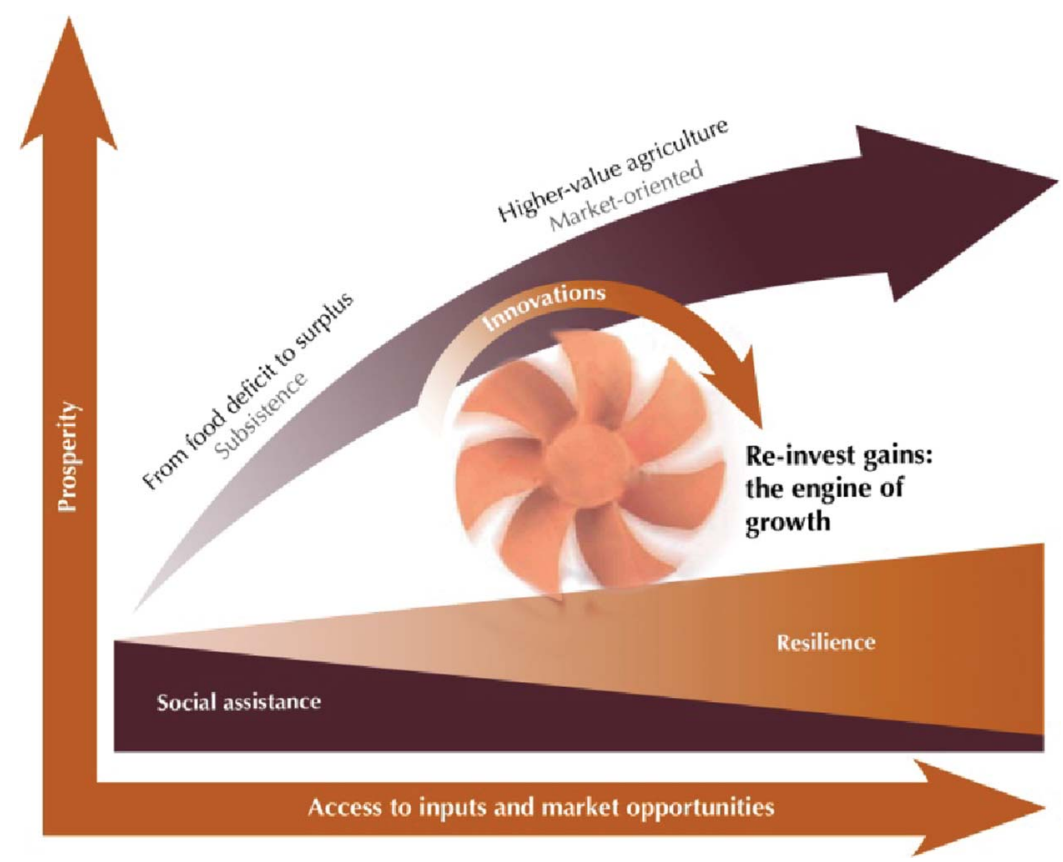

FIGURE 4 Inclusive market-oriented development: The conceptual framework for ICRISAT's Strategic Plan to 2020 (color figure available online).

stress, which in the drylands includes human, social, physical, natural, and financial stresses.

\section{CONCLUSION}

There is a consensus that the increasing concentrations of greenhouse gases in the atmosphere are raising global temperatures and changing the Earth's climate and prevailing weather patterns, with startling consequences. New knowledge and technical and policy solutions are critical if the rural poor in developing countries are to feel less pressure from climate change, high food prices, and environmental and energy crises. Given the adverse impacts of climate change on production and crop productivity and on the geographical distribution of pests, adaptation and mitigation strategies are crucial. A better understanding of climate change's impact on food production, forests, and natural resources to target and prioritize both adaptation and mitigation measures is possible when programs are implemented at the local level; are tailored to local circumstances and ecosystems are community-managed with immediate benefits for the communities and long-term benefits for future generations; are based on sound science; are enabled by effective policy at all levels; and are built on the current wealth of knowledge and new research directions. 


\section{REFERENCES}

Borrell, A. K., G. L. Hammer, and A. C. S. Douglas. 2000. Does maintaining green leaf area in sorghum improve yield under drought? I. Leaf growth and senescence. Crop Sci. 40:1,026-1,037.

Burney, J. A., S. J. Davis, and D. B. Lobell. 2010. Greenhouse gas mitigation by agricultural intensification. Proc. Natl. Acad. Sci. USA doi: 10.1073/ pnas.0914216107. www.pnas.org/cgi/doi/10.1073/pnas.0914216107

Food and Agriculture Organzation of the United Nations (FAO). 2009. Food security and agricultural mitigation in developing countries: Options for capturing synergies. Rome: FAO.

Hansen, J. W. 2002. Realizing the potential benefits of climate prediction to agriculture: Issues, approaches, challenges. Agric. Syst. 74:309-330.

Reddy, B. V. S., B. Ramaiah, A. Ashok Kumar, and P. Sanjana Reddy. 2007. Evaluation of sorghum genotypes for stay-green trait and grain yield. eJ. SAT Agric. Res. 3(1). http://www.icrisat.org/journal.

Sharma, H. C., S. Z. Mukuru, E. Manyasa, and J. W. Were. 1999. Breakdown of resistance to sorghum midge Stenodiplosis sorghicola. Euphytica 109:131-140. 